\title{
Synergy of Polyphenols as Strategy for Enhancing Bioavailability and Therapeutic Efficacy
}

\author{
Itodo S.E ${ }^{1}$, Amodu B ${ }^{1}$, Musa D.E ${ }^{3}$ \\ ${ }^{1}$ Department of Histopathology and Cytology, Jos University Teaching Hospital (JUTH) Jos Nigeria \\ ${ }^{2}$ Halamin Herbal centre, 10 George Innih Crescent, Apo District, Abuja Nigeria \\ ${ }^{3}$ Halamin Herbal centre, 10 George Innih Crescent, Apo District, Abuja Nigeria
}

\begin{abstract}
The search and identification of pharmacologically active compounds against cancer has focused primarily on the research of natural products and their synthetic analogues. Given this strategy, we evaluated the antimicrobial and antitumoral activity of SAABFAT 5. We also evaluated the carcinogenic property of metronidazole as the cancer inducing agent in the experimental animal. The extracts (200mg) of SAABFAT 5 were tested at $500 \mathrm{mg} / \mathrm{kg} /$ day
\end{abstract}

Background: An open label 3-week descriptive cross-sectional survey was conducted in a group of sheep to determine the efficacy of SAABFAT5: an ethnomedicinalpolyherbal formulation for the management of cancer

Method: The subjects in this study were nine sheep with an average weight of $20 \mathrm{~kg}$. The subjects were placed on SAABFAT 5, the ethnomedicinal herbal formulation for the prevention of liver cancer for a period of 3 weeks, and the subjects were monitored for a period of 8 weeks for possible relapse of signs and symptoms.

Results: subjects in this descriptive cross-sectional survey responded positively to the ethnomedicinal herbal formulation without any toxicity or side effects observed in the sheep for the 8 weeks monitoring period. However in group B animals fed with the carcinogen only, had a 100\% precancerous and cancerous cell as observed in the photomicrographs.

Conclusion: Chronic and debilitating disease is better managed with herbal supplement with little or no toxicity and side effects as compare to the conventional orthodox drugs with massive side effects and hepatotoxicity.

Keyword: Ethnomedicinal, SAABFAT5, Orthodox, Herbal, Formulation

\section{Introduction}

The use of herbal medicine dates back to thousands of years. Although it originated in India and China, it is widely practiced in Africa. Herbal therapy which started as folk medicine in most developed countries is becoming increasingly more popular with patients seeking alternative treatment options. Eisenberg et al., (1998) reported that, in developed countries the number of visits to the alternative medicine practitioners is growing rapidly with the number of visits in US was estimated to be 629 million in 1997; it was believed to have exceeded the number of visits to all primary care physicians. It is a known fact that, a large proportion of African population uses some form of alternative medicine and many do not inform their physician about it. Most patients seek alternative medicine because of lack of basic health facilities, when conventional therapy has failed or they feel the products have no side effects because they are of natural origin. Herbal therapy has also been used extensively in Nigeria. Although more than 80 percent of the people in both the underdeveloped and the developed countries depend on herbal medicines for their medical needs(WHO, 2002). The major problems with herbal medicines in such countries still remain their poor and sometimes unhealthy presentation.

Being faced with the panorama of resistivity and the attendant side effects associated with orthodox drugs, the focus is now being channeled to naturaceuticals also known as natural products. Bitter leaf botanically called Vernoniaamygdalina, is one of such products. Bitter leaf is a medicinal plant, which grows in the humid tropical secondary forests of Africa. Bitter leaf is among several natural products used by traditional healers in Western Nigeria to treat a number of bacterial infections. The leaves are used as a leafy vegetable for preparing the popular bitter-leaf soup and the juice or extract serves as a tonic drink. It contains $18 \%$ protein, 8.5\% fiber in a dry matter, and a good composition of macroelements(Egedigwe, 2010). Moreover, Vernoniaamygdalina has been used in traditional medicine as an antihelminth, an antimalarial, and a laxative herb (Challandet al; 2009). It was observed that an apparently sick wild chimpanzee chewed this plant to extract bitter juice and after a while it seemed to return to its normal activity.

These observations stimulated research on the chemical principals of Vernoniaamygdalina. Acording to Ademolaet al; (February 2011)Several stigmastane-type saponins such as vernoniosides A1, A2, A33, B2, B3, A44, and C5 have been identified in the leaves. It was shown that the A series of these saponins were bitter, mixtures of saponins as well as vernonioside A1 were shown to affect body and liver weights, urine and fecal 
output, and plasma and liver cholesterol concentrations in mice fed diets amended with these compounds.Avwioroet al; 2005). The antiplasmodial activity of some sesquiterpene and steroidal constituents of Vernoniaamygdalina was tested, and some were proved to be active against Plasmodium falciparum in vitro(Challandet al; 2009). The current search for potential anti oxidative principles to replace suspected tumour-causing synthetic analogues such as BHT7 necessitated this investigation.

Antioxidative principles have been implicated as parts of anticancer formulations and patents8. Although luteoline has been reported to be a strong antioxidant(Bhuyanet al; 2004), no report has so far been given on the antioxidative potentials of its tannin, alkaloid, anthroquinone, anthracyanosidic and glycosidic derivatives.

The present paper characterizes flavonoids, tannin, alkaloid, anthroquinone, anthracyanosidic and glycosidic derivatives of SAABFAT 5 with Vernoniaamygdalina leaves as one of its active ingredients.

This study is therefore designed to determine the clinical activities of SAABFAT 5 with Vernoniaamygdalina as one of its active ingredients, on animals infused with carcinogen.

\title{
II. Methodology
}

EXPERIMENTAL ANIMALS Nine sheep with an average weight of $20 \mathrm{~kg}$ each were used for this experiment. The sheep were kept in the animal house of the Ben Amodu farm and research centre, Abuja. They were acclimatized to the environment for 2 weeks. They were fed with commercial feeds pellet and clean water ad-libitum. The cages were cleaned daily

SOURCES OF VERNONIAL AMYGDALINA The leaves of Vernoniaamygdalina were harvested fresh from Ben Amodu's farm in kogi state, Nigeria; the required parts of these plants were collected carefully from the farm at the appropriate time. These parts were dried in the sun for one (1) day while it was subjected to seven (7) days air drying under a shade. Care was taken not to allow contamination of any sort. The plant was botanically identified by Dr. U.U Usman of the Botany Department, University of Agriculture Makurdi, Benue State. $150 \mathrm{~g}$ of the ground dried leaves of Vernoniaamygdalinawas extracted with 1 litre of hot water and another $150 \mathrm{~g}$ with 1 litre of $70 \%$ alcohol respectively.

SOURCES OF CARCINOGEN:Metronidazole is reasonably anticipated to be a human carcinogen based on sufficient evidence of carcinogenicity from studies in experimental animals. The metronidazole was obtained from H.J. Harkins company, Inc. USA.

\section{Hot Water Extraction}

A measured quantity (300g) of the ground Vernoniaamygdalinaleaves was dissolved in hot water, mixed by shaking vigorously. This was allowed standing for 1 hour, and then filtered to obtain the extract. The filtrate obtained was oven-dried to get rid of the residual water. $18 \mathrm{~g}$ of the extract was obtained.

\section{Using Alcohol as Solvent}

$300 \mathrm{~g}$ of ground Vernoniaamygdalinaleaves was dissolved in one liter (1L) of $70 \%$ alcohol (ethanol). This was allowed standing for 48 hours and then filtered to obtain the extract. The filtrate was oven-dried to get rid of the residual water; $20.24 \mathrm{~g}$ of the dry extract was obtained.

\section{Preliminary Phytochemical Screening.}

The extract of the Vernoniaamygdalina leaves was screened to determine the presence of the following metabolites through the preliminary phytochemical screening. The following active constituents and metabolites were tested for.
(i) Alkaloid
(ii) Flavonoid
(iii) Tannin
(iv) Cardiac glycosides
(v) Anthroquinone
(vi) Saponin
(vii) Anthracyanosides

\begin{abstract}
Alkaloids
The extract $(0.5 \mathrm{~g})$ was stirred with $5 \mathrm{ml}$ of dilute $\mathrm{HCl}$ on a stream bath; $1 \mathrm{ml}$ of the filtrate was treated with few drops of Mayers and a second $1 \mathrm{ml}$ portion was treated similarly with dragendoff's reagent and finally another lml portion with wagner's reagent.
\end{abstract}


Synergy of Polyphenols as Strategy for Enhancing Bioavailability and Therapeutic Efficacy

\begin{tabular}{lll}
\hline Test & Observation & Inference \\
\hline $\begin{array}{l}\text { Alkaloid } \\
\text { (i) 1ml of extract }+ \text { few drops of }\end{array}$ Yellowish brown colour & Alkaloid inferred \\
Drangendoff's reagent \\
$\begin{array}{l}\text { (ii) 1ml of extract }+ \text { few drops of } \\
\text { Mayers reagent }\end{array}$ & Yellowish colour seen & \\
\hline (iii)1ml of extract + Wagner's reagent & Dark turbid brown & Alkaloid inferred \\
\hline
\end{tabular}

\section{Tannins}

Each portion of alcohol and water extract $(5 \mathrm{~g})$ was stirred with $10 \mathrm{ml}$ of alcohol and distilled water respectively. They were filtered and ferric chloride reagent was added to filtrates and $1 \mathrm{ml}$ portion of the extract was treated with bromine water.

\begin{tabular}{lll}
\hline Test & Observation & Inference \\
\hline (i) $1 \mathrm{ml}$ of extract $+\mathbf{1 m l}$ ferric chloride & Blue black precipitate & Catecol tannin present \\
\hline (ii)of extract + bromine water & Brownish red turbid & Condensing tannins \\
\hline
\end{tabular}

\section{Flavonoid}

(i) Lead Acetate Test: $0.2 \mathrm{ml}$ of the extract was added to $0.2 \mathrm{ml}$ 0f $10 \%$ Lead acetate, the mixture was gently shaken to avoid emulsion.

(ii) Ferric Chloride Test: $0.2 \mathrm{ml}$ of $10 \%$ ferric chloride was added to the extract. The mixture was shaken together to observe colour.

(iii) Sodium Hydroxide Test: $0.2 \mathrm{ml}$ of dilute $\mathrm{NaOH}$ was added tom $0.2 \mathrm{ml}$ of the extract shaken gently.

\begin{tabular}{lll}
\hline Test & Observation & Inference \\
\hline (i) Lead acetate on extract & Dirty brownish precipitate & Flavonoid present \\
(ii) ferric chloride test & Wooly brownish colour & Flvonoid present \\
\hline (iii) Sodium hydroxide test & Golden yellow precipitate obtained & Flavonoid present \\
\hline
\end{tabular}

\section{Cardiac Glycoside}

(i) Kedde's Test: $1 \mathrm{ml}$ of $8 \%$ solution of the extract was mixed with $1 \mathrm{ml}$ of $2 \%$ solution of 3,5 dinitrobenzoic acid in methanol and $1 \mathrm{ml}$ of $5.7 \%$ aqueous sodium hydroxide

(ii) Liebermann-burchard Test: The Vernoniaamygdalina extract (0.5) was dissolved in $2 \mathrm{ml}$ of acetic anhydride and cooled well in ice., concentrated sulphuric acid was carefully added.

(iii) Salkwoski's Test

$0.5 \mathrm{~g}$ of the Vernoniaamygdalina extract was dissolved in $2 \mathrm{ml}$ of chloroform, concentrated sulphuric acid was carefully added to form lower layer.

(iv) Keller Killiani's Test: The extract of the Vernoniaamygdalina $(0.5 \mathrm{~g})$ was dissolved in $2 \mathrm{ml}$ of glacial acetic acid containing one drop (1 drop) of ferric chloride solution. This was under-layered with concentrated sulphuric acid.

\begin{tabular}{llll}
\hline Test & Observation & Inference \\
\hline (i) & Kedde's Test & Canclenolide \\
(ii) Lieberman's Test & Deep greenish blue & Steroid nuclei inferred \\
\hline (iii) Salowiski's Test & Reddish brown colour at interface & $\begin{array}{l}\text { Deoxysugar,characteristics } \\
\text { cardenolide }\end{array}$ & of \\
\hline
\end{tabular}

\section{Anthraquinone Glycosides}

These occurred in both free and bound form

(i) Free Anthraquinone: The extract $0.1 \mathrm{~g}$ was dissolved with $10 \mathrm{ml}$ hot water for aqueous extract and $10 \mathrm{ml}$ of alcohol extract, both were put in water bath to steam for 5 minutes, the solution were filtered hot, the filtrate were extracted with chloroform layer was taken off. This layer was washed with $5 \mathrm{ml}$ of water and was shaken with $5 \mathrm{ml}$ ammonia solution.

(ii) Bound Anthraquinone

A second set of the mixture was prepared with $0.1 \mathrm{~g}$ of the extract with $10 \mathrm{ml}$ of ferric chloride solution and $5 \mathrm{ml}$ hydrochloric acid. The sample was hydrolyzed by heating on water bath for 10 minutes, filtered hot and treated as with free anthraquinone. 
Synergy of Polyphenols as Strategy for Enhancing Bioavailability and Therapeutic Efficacy

\begin{tabular}{lll}
\hline Test & Observation & Inference \\
\hline Free anthraquinoneBontrager's test & $\begin{array}{l}\text { Presence of red colour in ammonia } \\
\text { upper phase. }\end{array}$ & Free anthraquinone present \\
\hline
\end{tabular}

\section{Saponins}

The ability of saponin to produce frothing in aqueous solution and to haemolyse red blood cells was used as screening.

(i) Frothing Test: A little portion of the extract was shaken with water in a test tube.

(ii) Haemolysed Test: Exactly $0.2 \mathrm{~g}$ Vernoniaamygdalina extract was dissolved in $10 \mathrm{ml}$ of warm water and filtered, remaining the filtrate. $2 \mathrm{ml}$ of $1.8 \%$ sodium chloride $(\mathrm{NaCl})$ solution was put into two test tubes. To one of these $2 \mathrm{ml}$ distilled water was added. The concentration of sodium chloride in each test tube was isotonic with blood serum. Five drops of blood were added to each tube and the tubes were inverted gently to mix the contents

TABLE 1: ADMINISTRATION OF EXTRACT AND THE CARCINOGEN

\begin{tabular}{llll}
\hline Groups & & Dose $(\mathrm{mg} / \mathrm{kg})$ orally & Duration in days \\
\hline (A) & SAABFAT 5 & $200 \mathrm{mg}$ & 21 \\
& & & 21 \\
\hline
\end{tabular}

TABLE 2: ADMINISTRATION OF THE CARCINOGEN ALONE

\begin{tabular}{lll}
\hline Groups & $\mathrm{mg} / \mathrm{kg} / \mathrm{Day}$ & Duration in Days \\
\hline (B)Metronidazole & 500 & 21 \\
(C)Control (distilled water) & - & 21 \\
\hline
\end{tabular}

The administration of the extracts lasted for 21 days. The extracts and the carcinogen were mixed with small quantity of the animals' feed for those in group A before they were given while the carcinogen with the small quantity of the animals' feed were given separately for those in group B. Group A animals were given $200 \mathrm{mg} / \mathrm{kg} / \mathrm{day}$ of the extract and the carcinogen, Group B animals were given $500 \mathrm{mg} / \mathrm{kg} / \mathrm{day}$ of the carcinogen and the animals' feed and Group $\mathbf{C}$ animals were given distilled water. The animals were watched closely and vital signs taken for the period the experiment lasted and were euthanatized at the end of the 21 day. Cotton wool was dipped into chloroform and the animals were allowed to inhale the chloroform in a desiccator. They were opened up and the liver and kidney were harvested. The selected pieces of tissue were processed into paraffin wax, sectioned at $5 \mu \mathrm{m}$ and stained by the $\mathbf{H}$ and $\mathbf{E}$ method, and Perl's Prussian blue method. The stained slides were examined under the microscope and photomicrographs needed were taken.

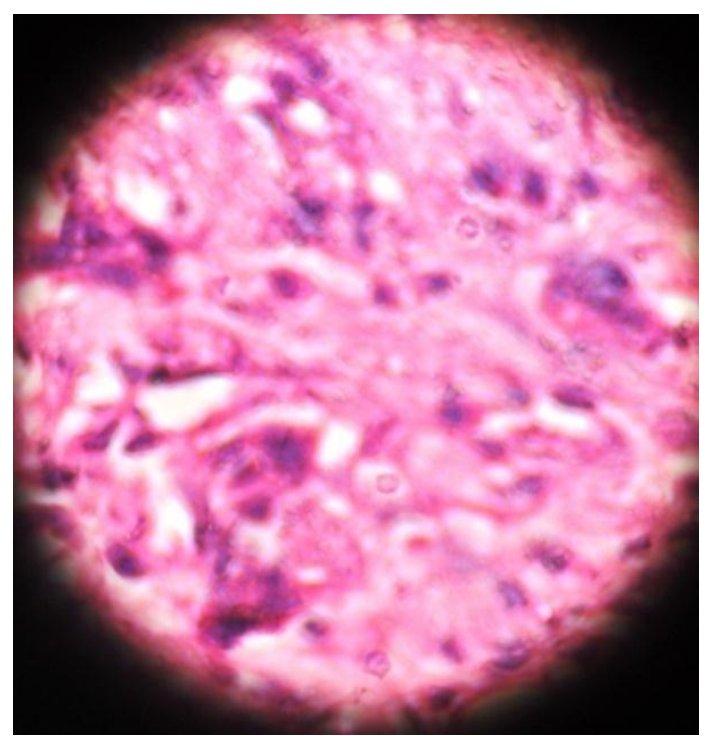

Figure 1: Hepatocellular carcinoma $(\mathrm{H} \& \mathrm{E}, \mathrm{X} 40)$ - seen in animals' in group B 


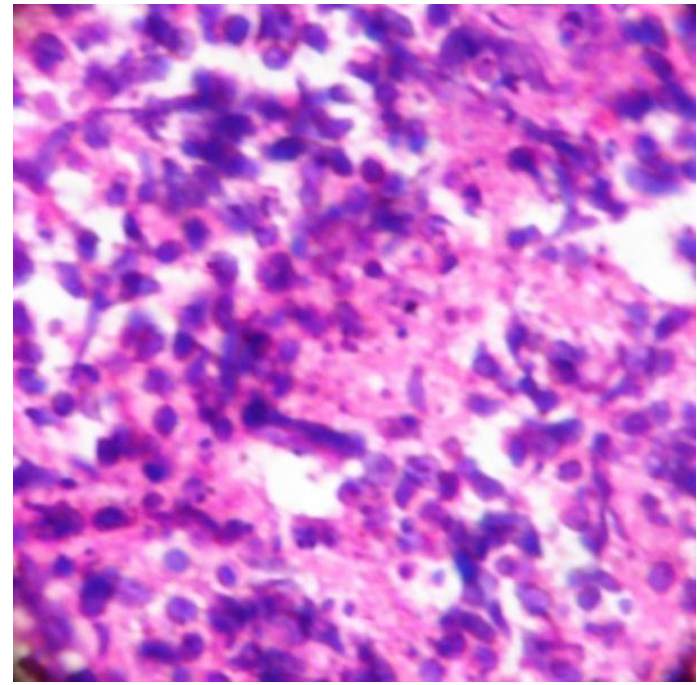

Figure 2 : Hepatocellular carcinoma $(\mathrm{H} \& \mathrm{E}, \mathrm{X} 40)$-seen in animals' in group B

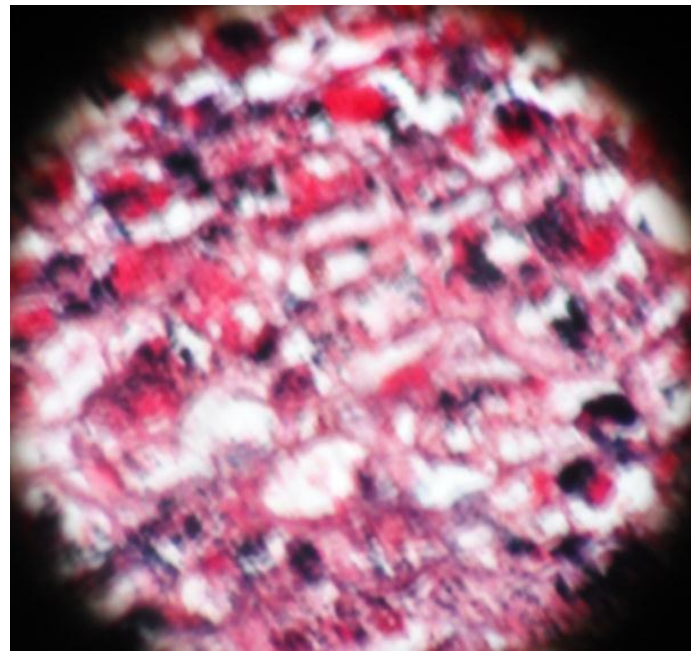

Figure 3 : Haemosiderin pigment in hepatoma(Perl's Prussian Blue, X40) -seen in animals' in group B

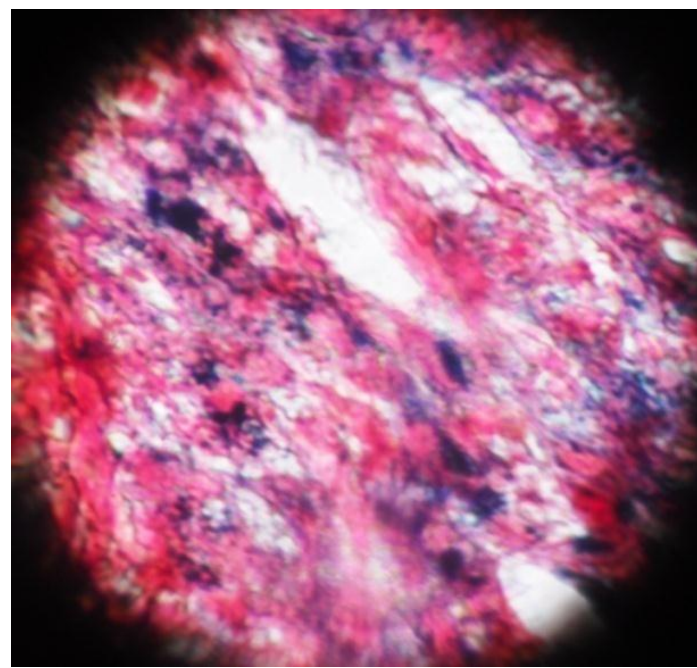

Figure 4 : Haemosiderin pigment in hepatocellular carcinoma (Perl's Prussian Blue, X40) -seen in animals' in group B 


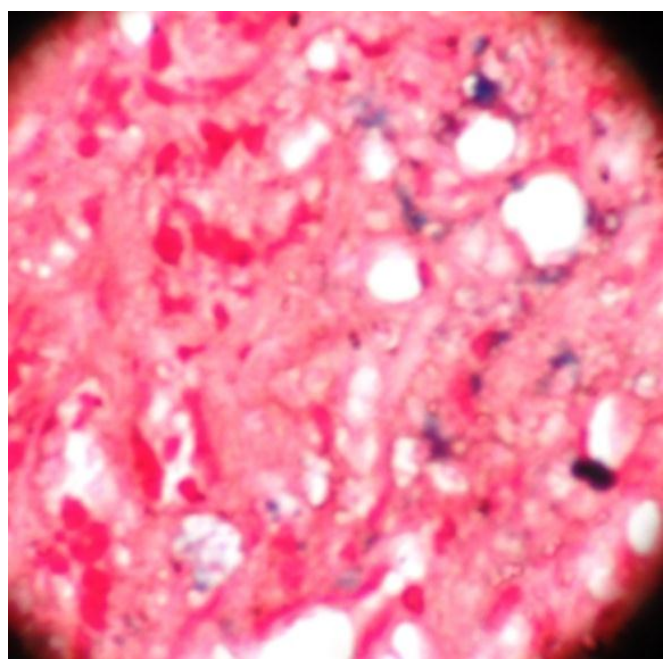

Figure 5 : Haemosiderin pigment in Hepatic flexus with well -differentiated adenocarcinoma (Perl's Prussian Blue X40)-seen in animals' in group B

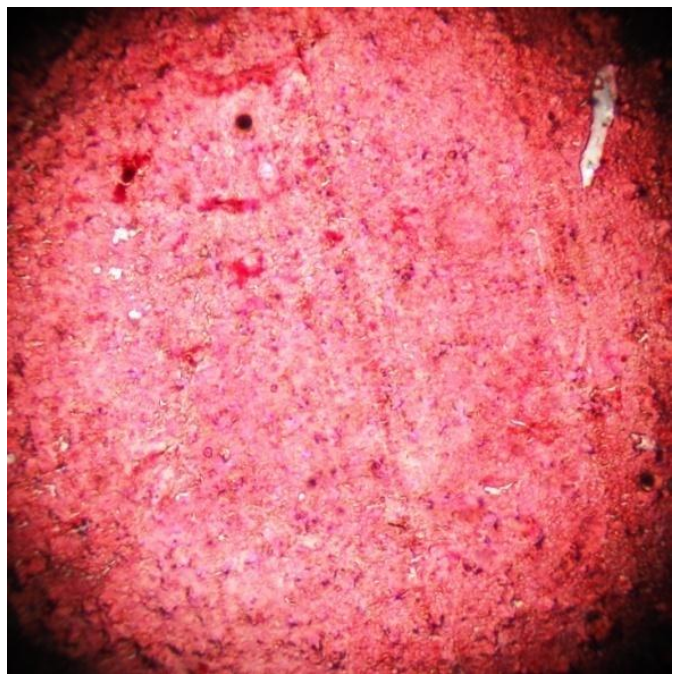

Figure 6 : Hepatoblastoma (Perl's Prussian Blue technique, X10) - seen in animals' in group B

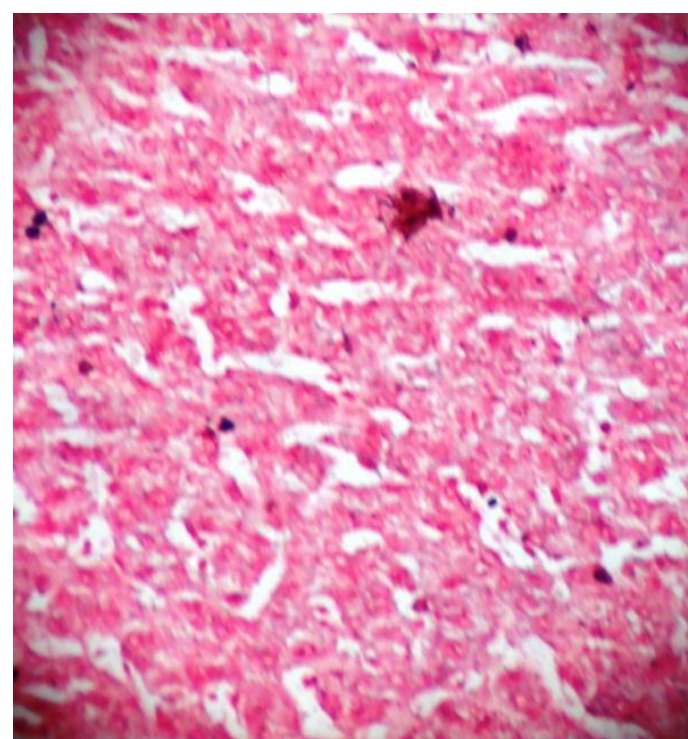

Figure 7 : Haemosiderin pigment in cholioangiocarcinoma(Perl's Prussian Blue, X10) -seen in animals' in group $B$ 


\section{Body Weight}

The body weight for both the experimental and control animals were taken before and during administration of the extract at interval of 5 days . The mean body weight of each group were calculated and represented on the graph as shown below.

TABLE 3: MEAN BODY WEIGHT FOR EACH GROUP

\begin{tabular}{|c|c|c|c|c|c|c|}
\hline Group & & Day 0 & Day 5 & Day 10 & Day 15 & Day 20 \\
\hline (A) & Extract with carcinogen $(200 \mathrm{mg} / \mathrm{kg})$ & 17.67 & 19.03 & 19.87 & 20.25 & 19.69 \\
\hline (B) & Carcinogen alone $(500 \mathrm{mg} / \mathrm{kg})$ & 20.32 & 20.37 & 20.22 & 20.37 & 20.37 \\
\hline (C) & Control (distilled water) & 18.00 & 18.09 & 20.10 & 20.12 & 20.25 \\
\hline
\end{tabular}

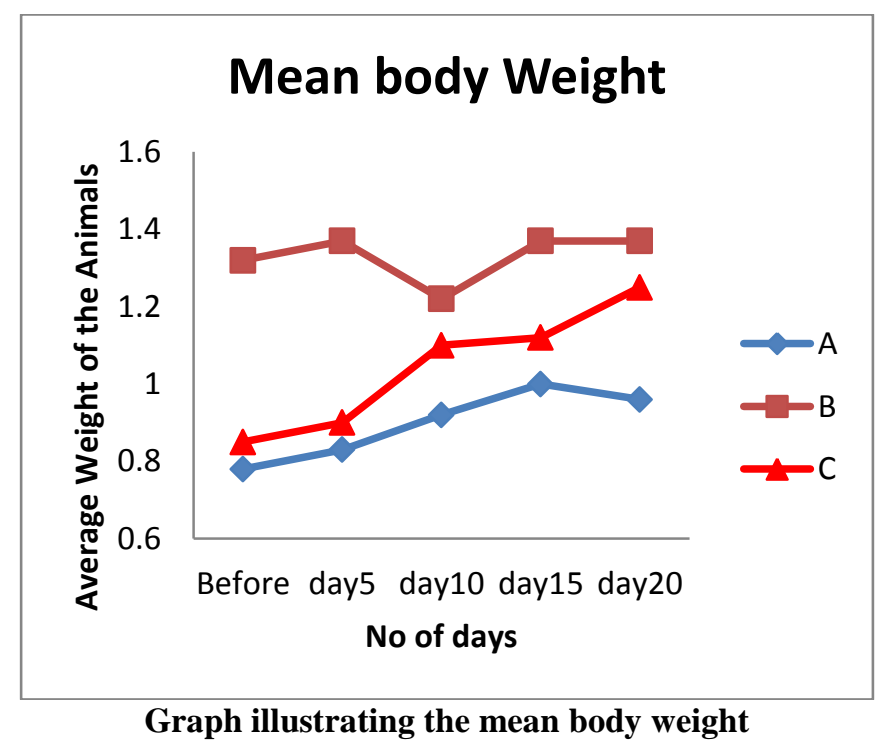

RECTAL TEMPERATURE AND VITAL SIGNS:The rectal temperature taken was to ensure the animals were not sick. This was also done during administration days. The temperature falls in the normal range of $37-$ 39 degree Celsius for rabbits.

FIVE DAYS AFTER THE INITIAL ADMINISTRATION OF THE EXTRACTS AND THE CARCINOGEN:The group A that was administered the extracts and the carcinogen were moving freely without any sign of sickness while in group B that was administered the carcinogen without the extract were seen with swellings on the eyes, breast and scrotum. There was palpable loss of hairs, nose bleeding and weight loss.

\section{Discussion}

There was reduction in the body weight of group $\mathbf{A}(200 \mathrm{mg} / \mathrm{kg})$ animals at about day 15 of the administration. This effect of decrease in body weight manifest at around day 5 in group $\mathbf{B}(500 \mathrm{mg} / \mathrm{kg})$, but they started increasing in weight again around day 10.The reduction in weight was as a result of the extract, because group $\mathbf{C}$ (control) does not show any reduction in body weight at all. This is in agreement withEgedigweet al; 2010 in Nigeria, although abino rats were used but the common underlining denominator was the remarking reduction in weight of the abino rat that vernoniaamygdalina was not incorporated in their feed.Statistical analysis done shows that the reduction in the body weight is not significant statistically with none of the group having a p-value less than 0.05 . The rectal temperature taken shows that the extract does not cause pyrexia in the experimental animals and along with control group all are having temperature that falls between the normal range of 37-39 degree Celsius. Five days after the administration of the extract and carcinogen respectively, the group A that was administered the extracts and the carcinogen were moving freely without any sign of sickness while in group $\mathbf{B}$ that was administered the carcinogen without the extract were seen with swellings on the eyes, breast and scrotum, there was a palpable loss of hairs, nose bleeding and weight loss. This again is in agreement with Amoduet al; 2013 in Nigeria.There was reduction in the body weight of group $\mathbf{A}(100 \mathrm{mg} / \mathrm{kg})$ animals at about day 15 of the administration. This time variation in the weight reduction is central to the dosage used in 
this work. The histological section demonstrated by Perls Prussian blue reaction shows no iron deposition in the kidney section of both control and experimental animals. Liver section from group $\mathbf{A}(200 \mathrm{mg} / \mathrm{kg}$ ) show deposition of iron which were in the same quantity with group $\mathbf{C}$ (control) and are limited within the hepatocytes but group B $(500 \mathrm{mg} / \mathrm{kg})$ shows more of iron deposition that extended into the portal region. The kidney section demonstrated using $\mathbf{H}$ and $\mathbf{E}$ in group Ashows normal histology of the kidney, but in group $\mathbf{B}$ renal tubules contain cellular debris, lobular disarray and a lot of pyknotic cells suggestive of acute tubular necrosis which may be due to the effect of the carcinogen while the section from group $\mathbf{C}$ animals also appears normal. he liver section from all the groups shows normal hepatocytes, but there was periportal necrosis in one of the animals in group A $(100 \mathrm{mg} / \mathrm{kg})$.In group B $(500 \mathrm{mg} / \mathrm{kg})$ canaliculi were dilated, filled with bile and central vein with blood and cellular debris, lobular disarray and a lot of pyknotic cells which may be as a result of the carcinogen.

\section{Conclusion}

SAABFAT 5 with Vernoniaamygdalina as it active ingredient had been used in traditional medicine for the treatment of various ailments (Igileet al.,2004),it has been used to treat gastrointestinal disorders, haematoma, malaria, inflammation, cancer etc. The methanolic extract of the leaves was investigated on the histology of the liver and kidney. The kidney section demonstrated by Perls Prussian blue reaction shows no iron deposition. The liver sections show more of iron deposition with the carcinogen. There were no significant histological deviation observed in the kidney and liver section of experimental animals compared with control demonstrated by Haematoxylin and Eosin staining technique.

\section{Reference}

[1]. Avwioro OG, Aloamaka PC, Ojianya NU, Oduola T, Ekpo EO (2005).Extract of Pterocarpusosun as a histological stain for collagen fibres. Af. J. Biotch vol. 4(5), 460-464

[2]. Avvwioro OG (2002).Histochemistry and tissue Pathology claverianum press Ibadan Nigeria. 134- 213

[3]. Baker FJ, Silverton RE (1976). The Theory of Staining.Introduction to Medical Laboratory Technology 6th ed. Butterworth.385391.

[4]. Banejee A, Mukherjee AK. (1981). Chemical Aspects of Santalin as a Histological Stain. Stain Technol. 56:83-85

[5]. Bhuyan R, Saikia CN (2004). Isolation of colour components from native dye-bearing plants in Northeastern India. Am. J. Pathol, 164(5): 873-79

[6]. Carleton HM, Drury RAB, Wallington EA, and Cameron R (1976).Histology Technique, 4th ed. Oxford University Press Lond. 99-100

[7]. Challier B. PernauJ, and Viel J (1998). Garlic, Onion and cereal Fibreas Protective for Breast Cancer: A French case Study. European Journal of Epidemiology. $14: 739$ - 747.

[8]. Culling CFA (1974).Handbook of Histological and Histochemical techniques.3rd ed. Butherworths Co. Ltd London. $151-164$.

[9]. DorschE, and Wagner H. (1999). New atlasmathic drugs from tradiyional medicine? Int Arch Allergy ApplImmunol. 94: 262- 265

[10]. Dorant E, Van Din Brandt P. and Goldbohm R (1994). A Prospective Cohort Study on Allium Vegetable Consumption, Garlic Suplement Use, and the Risk of Lung Carcinoma in the Netherlands. Cancer research: 6148- 6153.

[11]. Eom S, Shin D, and Yoon K (2001). Improving the Dye Ability of Natural Colourants on Cotton by Cationization. Ind. J. Fibre Text. Res. 26(4): 425-431

[12]. Fitzpatrick D, Hirschfield S and Coeffery R (1993). Endothelium-dependent vasorelaxing activity of the wine and other grape products. The American Physiological Society.H774-H778.

[13]. Garg A, Shenda S and Gupta KC (1991). Effect of Mordant on Colourof Natural Dye Extracted from Tissue Flowers (Buteamongsperma). Colourage 38(2): 50-53

[14]. Gazzani G, Papetti A, MassoliniG and Daglia M (1998). Protective Activity of Water Soluble Companents of some Common Diet Activity in Onion in sulfur Dependent Thrombosis and Haemostasis, 460-462.

[15]. Harvey MD, and John UL (1998).Kings American's dispensary Allium cepa. Onion

[16]. Hertog M, Kromhout D, Aravanis C, Blackburn H, Buzina R, Findanza F,

[17]. Giampaoli S, Jansen A, Menotti A, Nedeljokovic S, Pekkarinen m, Simic B, Toshima H, Feskens E, Holiman P, and Katan M (1995). Flavonoid Intake and long Time Risk of Coronary Heart Disease and Cancer in the Seven Countries study. Arch Intern. Med 155: 381 - 386

[18]. Hoffman EM and Bauknecth N (1999). A Dye Binding Assay for the Quantification of Solution and Cell-bound Acidic Polyssccharides Produced by Red Algae. Anal.Biochem. 267(2): 245 - 251

[19]. Hu J Vecchia c, Negri E, chatenoud L, Bossetti C, Jia X, Liu R, Huang G, Bi D

[20]. and Wang C. (1999). Diet and Brain Cancerin adults; a case control studies in Northeastern China Int. J. cancer 81: 20-23

[21]. Hugues D, and Plulippe DEL: African Garden and Orchards published by Mackmallian 315

[22]. Malaveili C, Hautefeuille A, Pignatelli B, Talaska G, Vineis P and Bartsch H

[23]. (1996). Dietary Phenolic as Anti-Mutagen and Inhibitory of Tobacco Related DNA Adduction in the Urothelium of Smokers. Carcinogenesis 17(10): 2193- 220

[24]. Egedigwe CA (2010). Effect of dietary incorporation of Vernoniaamygdalina and Vernoniacolorata on blood lipid profile and relative organ weights in albino rats (Thesis).Department of Biochemistry, MOUAU, Nigeria.

[25]. Challand S, Willcox M (2009). A clinical trial of the traditional medicine Vernoniaamygdalina in the treatment of uncomplicated malaria.JAltern Complement Med15 (11): 1231-7. doi:10.1089/acm.2009.0098. PMID 19922255.

[26]. Ademolaet al February 2011. Anthelminthic activity of acetone extract and fractions of Vernoniaamygdalina against Haemonchuscontortus eggs and larvae".TropAnim Health Prod43 (2): 521-7.

[27]. AmoduB ,Itodo SE, Musa DE (2013). Tabsaabr: A Novel ethnomedicinalpolyherbal formulation for the radical rapid cure for tuberberculosis. 